\title{
Archimedes in Cephalonia and in Euripus Strait: Modern Horizontal Archimedean Screw Turbines for Recovering Marine Power
}

\author{
A. Stergiopoulou ${ }^{1}$ and V. Stergiopoulos ${ }^{2, *}$ \\ ${ }^{1}$ Department of Water Resources and Environment Engineering, School of Civil Engineering, National Technical University of Athens, \\ Athens 15780, Greece. \\ 2. Higher School of Pedagogical and Technological Education, Division of Hydropower, ASPETE Campus, Athens 14121, Greece.
}

Received 3 March 2013; Accepted 3 May 2013

\begin{abstract}
The possibility of exploiting sea and tidal currents for power generation has given little attention in Mediterranean countries despite the fact that these currents representing a large renewable energy resource could be exploited by "modern old technologies" to provide important levels of electric power. It is also well known that one of the oldest machines still in use is the Archimedes screw, a device for lifting water for irrigation and drainage, invention credited to Archimedes. The main aim of this paper is to present a new small hydro philosophy of recovering the unexploited coastal and tidal hydraulic potential by following an efficient "Archimedean philosophy" and by using modern horizontal-axis unconventional cochlear turbines. Our work proposes "the presence of Archimedes in Cephalonia and in Euripus Strait" and the optimal "Archimedean" exploitation of the Euripus tidal current and of the Cephalonia coastal paradox cross flowing continuously from Livadi Gulf to the Gulf of Sami. The present paper intends to prove the useful modern rediscovering of some old Archimedean ideas concerning spiral water wheel technologies under the form of new and efficient horizontal-axis Archimedean hydropower turbines.
\end{abstract}

Keywords: Archimedean screws, Small hydropower, Euripus Strait, Cephanonian paradox)

\section{Introduction}

Sea and tidal currents for power generation has given little attention in Europe, in Mediterranean countries and in Greece, despite the fact that such currents, representing a large renewable energy resource, could be exploited by modern technology to provide impressive levels of electric power and give a significant contribution to fulfilling the energy demand. It is well known that one of the oldest hydraulic machines still in use is the spiral screw pump of Archimedes, a device for lifting water for irrigation and drainage, invention credited to Archimedes. This paper presents some modern old Archimedean screw ideas for recovering Mediterranean Sea power and most especially recovering the unexploited potential of Cephalonian paradox and the tidal current of Euripus Strait. The proposed here "presence of Archimedes in Cephalonia and in Euripus" concerns the rediscovering of the always modern Archimedean ideas and philosophy by using innovative sea floating Archimedean cochlear rotors, based on the energy flow inversion in their spiral pump operation. The beautiful island of Cephalonia is known above all for its sea katavothres and its coastal cross flow paradox. This island is the site of one of the most astonishing hydrological phenomena in the world [1].

A strange seawater massive current flows continuously into the karst substratum of the island through sinkholes, in Livadi Gulf, near Argostoli. The present work tries to

\footnotetext{
*E-mail address: bstergiopoulos@aspete.gr
}

ISSN: 1791-2377 @ 2013 Kavala Institute of Technology. All rights reserved. describe some quite simple physical models for the hydraulic explanation of the strange cross-flow Cephalonia's coastal paradox and to find hydraulic correlations with a strong lost and forgotten water near-shore processes memory $[2,3]$. This seawater current disappearing in the water channel entrance in Livadi Gulf reappears on the opposite coast of the island at brackish springs, near the town of Sami as shown in Fig. 1. This Mediterranean exclusive special feature of Cephalonia with the continuous seawater current inflow in Livadi gulf and outflow in Sami's gulf after a strange disappearance into island's rock body seems to be a real world unique sea hydraulic mystery, the Cephalonia's coastal paradox. Passing from Ionian to Aegean Sea, the coastal mystery of Cephalonia sea-river finds its hydraulic flow analogue in the tidal current of Euripus Strait. Since ancient times several philosophers, scientists, travellers and authors have studied the complex tidal problem of Euripus.

Early explanations for the tides were curious. Aristotle is credited with the law that no animal dies except when water is ebbing. This idea survived into popular culture. For example in many Mediterranean countries, tide's phase was recorded at the time of each person's death. Ancient Greek or Eastern cultures and the Gaia Hypothesis of J. Lovelock held the belief that the water was the blood of the Earth and that tides were caused by the Earth breathing [4]. The conventional method of extracting energy from tidal flows is to place a barrage across an estuary with large tidal range to create a static head or pressure difference, ${ }_{2}$ and operate a low head hydroelectric power plant with intermittent, reversing flow. The best-known example of this approach is the installation in "La Rance" River Estuary in France, 
completed in 1966. The less well-known method of extracting energy from tidal and other sea flows is to convert kinetic energy of moving water directly to mechanical shaft power without otherwise interrupting the natural flow, in a manner analogous to a hydraulic-wind turbine. The Euripus Strait shown in Fig.2 is a narrow channel of water separating the island of Euboea from Boeotia. The strait's principal port is Chalcis on Euboea, located at the strait's narrowest point. The "old" or "low" or "sliding" Chalcis bridge lies across midtown, and can slide away to allow shipping traffic. It is located at the narrowest strait's point, where it is only $38 \mathrm{~m}$ wide. It was originally built as a retractable bridge in 1858 , replaced by a rotating one in 1896 . The existing bridge build in 1962, following the excellent ideas and designs of Professor Theodosios Tassios, was extensively refurbished in 1998. The strait is subject to strong tidal currents, which reverse direction approximately four times a day.

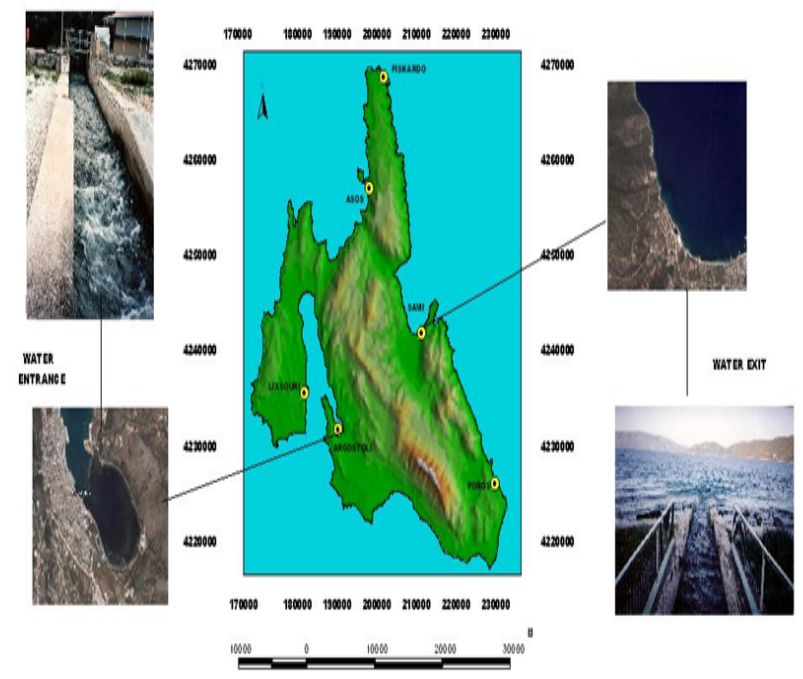

Fig. 1. Schematic representation of the most astonishing hydraulic phenomenon in the world.

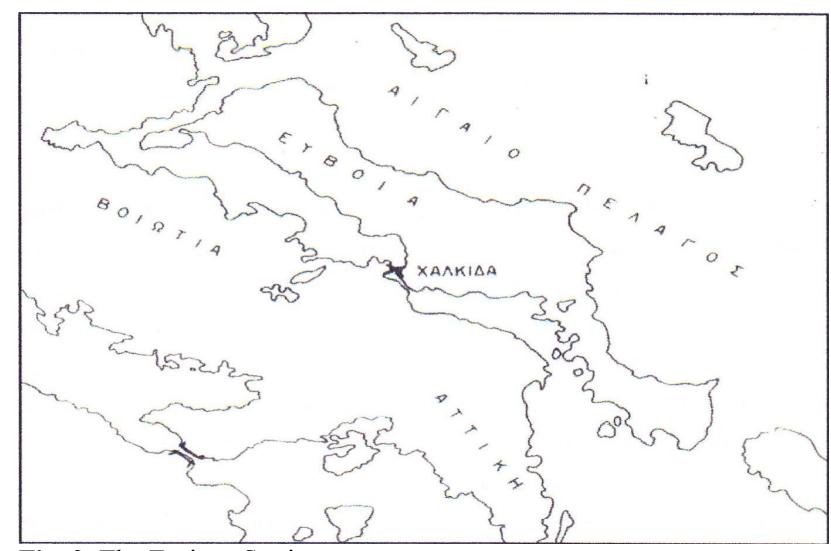

Fig. 2. The Euripus Strait.

\section{Cephalonia's Mysterious Sea River}

The total area Cephalonia's island belonging to Ionian Islands area is approximately $808 \mathrm{Km}^{2}$. The core of the main body of this karst island is the Ainos's mountain chain rising as much as $1628 \mathrm{~m}$ above sea level. The climate of Cephalonia is Mediterranean with high relative humidity and great annual and monthly precipitation. In particular, the mean annual precipitation of Cephalonia is $1000 \mathrm{~mm}$, the double than it is to eastern Greece.

It is known that Ionian Islands have the privilege of having a great quantity of hydrological entries. Cephalonia's geological substance consists of calcareous formations. According to Bonacci's Karst Hydrology the only permanent sea katavothres in the world, is the case of Cephalonia's island [5]. Generally Cephalonia's katavothres, swallowing sea water permanently, are well-organized fissures in the karst mass through which water sinks underground and they play an important role, from hydraulic and hydro-geologic standpoint of view, in whole water karst flow. This strange strong seawater current is disappearing continuously in Livadi Gulf through sinkholes, which have formed in fractures in the rock (Triassic, Jurassic, Cretaceous and Cenozoic limestone and dolomite). This seawater current reappears on the opposite coast of the island at brackish springs, near Sami's town.

The underground seawater current route between Argostoli and Sami is about $15 \mathrm{Km}$ long. Figure 3 represents schematically this Cephalonian paradox. Such inflow outflow seawater current phenomenon has not been observed in other karst islands in Mediterranean or in other parts of the world.

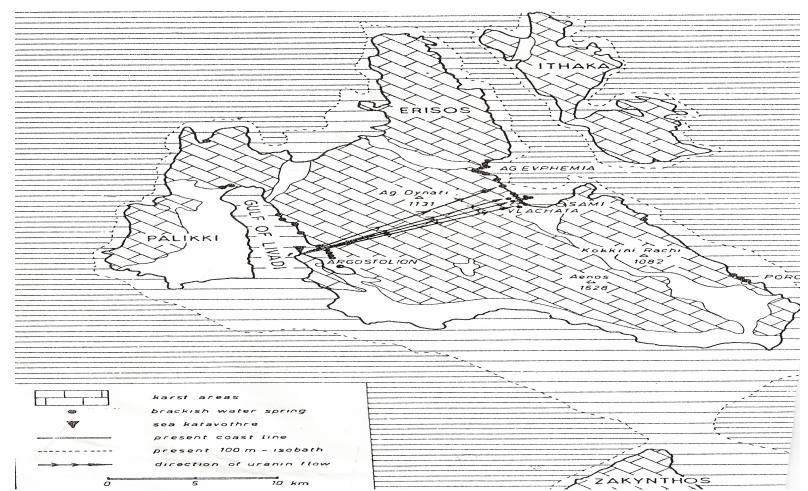

Fig. 3. Schematic representation of the Cephalonian paradox

There must necessarily be a continuous source of energy to cause this hydraulic phenomenon of the continuous inflow of water below sea level, since the latter represents minimum potential for water, in the field of terrestrial gravity. However, it is well known that an important continuous marine current, follows the Aegean current, which runs round the southern coast of Greece and joins the Adriatic circuit currents, and touches the island of Cephalonia. As seen in Fig.4 the question is, "has this Aegean - Adriatic current a strong correlation with Cephalonia's flow paradox?"

The nature of the energy source that probably causes this phenomenon is directly related to the existence of a marine current, which creates a hydraulic gradient between the two sides of the island, but with inflow being maintained by density flow. This is made possible by a deep karst conduit created during the Cainozoic period and which runs in the same direction as the marine current. It seems also that route of the important continuous SSE-NNW marine current touches Cephalonia, following the Aegean current, which runs round the southern coast of Greece and joins the Adriatic circuit currents to the NNW direction. It is very probable that this Aegean - Adriatic large scale current could have a strong correlation with Cephalonia's paradox [6]. 


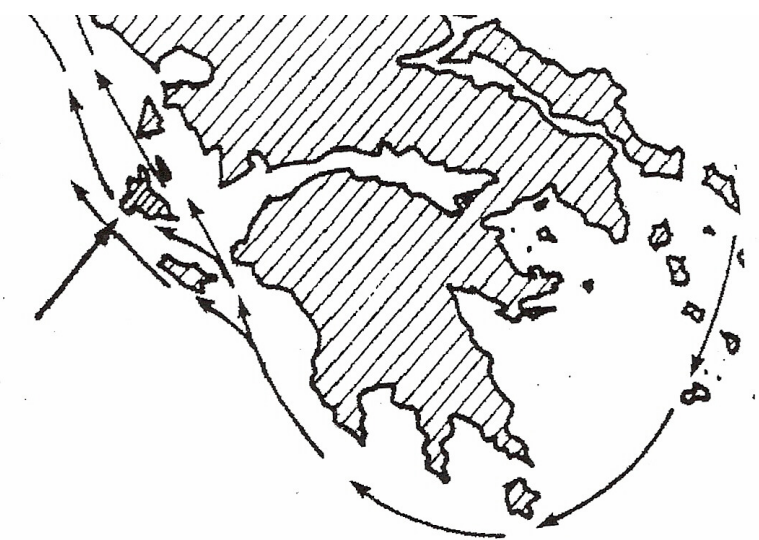

Fig. 4. Has this Aegean - Adriatic current a strong correlation with Cephalonia's flow paradox?

However, which is the main energy source of this strange current motion, not observed in other karst Mediterranean islands or in other parts of the world? Is the Cephalonia's paradox generated by tides? Is it probably due to the density differences caused by salinity or temperature variation?

Are there some other local effects of karst features playing a role on water's circulation in carbonate rocks, coastal areas like the permanent sea - water current throughout whole Cephalonia's mountainous range? Is the energy of Aegean-Adriatic marine current probably the main cause of this phenomenon? Who maintains and accentuates the movement? Does the presence of karst labyrinth conduits play a certain role in the whole throughout current flow? Is it possible to occur simultaneously, various factors, like the energy of Aegean-Adriatic marine current, density flow and the presence of karst conduits, for controlling the whole phenomenon [6, 7]? Which is the role of Ghyben-Herzberg ratio of fresh and salt-water density to the dynamic interface of this unusual marine current phenomenon [7, 8]? The principle of equilibrium due to the difference in density between fresh water and sea water in coastal areas may be applied not only to lateral encroachment of sea water in carbonate rocks but also to vertical movement of salt water through solution openings in Cephalonia's island.

The Cephalonia's paradox is made even more interesting by the fact, that some similar but quite simple cases well known in other countries, with intake of seawater, but without underground flow across the whole core of an island, have been explained by various mechanisms, the most common of which is connected with ocean tides. Furthermore, at some other coastal springs, sea level is temporarily higher than the level of adjacent underground water, during exceptionally high tides, and salt water may then run into the springs. In these cases the seawater is discharged at low tide and the springs flow normally again. It seems also that strong winds from the sea can have a similar effect to that of tide by submerging the coast and causing temporary penetration of seawater into the substratum.

Whatever, the mechanism involved in other current phenomena, intake of seawater is always temporary, whereas at Cephalonia salt water runs throughout the island continuously. It is therefore not possible to seek the cause of the phenomenon in periodic tides or winds, which are not constant in either force or direction. Various hypotheses could be put forward to approach this physical mechanism and to explain this strange flow paradox. Many factors occur simultaneously in this exceptional Cephalonia's karst sea current flow case and probably play an important role in the characteristics of seawater inflow and brackish water outflow. The energy of Aegean-Adriatic marine current probably causes the phenomenon. Density flow must then accentuate and maintain the movement. Finally, the process is made possible by the existence of karst conduits which were probably formed after Tertiary period and which lie in a similar direction to that of the marine current.

The principle of equilibrium due to the difference in density between fresh water and seawater in coastal areas may plays an important role in lateral encroachment of sea water in carbonate rocks and also in the vertical movement of salt water through solution openings at the island. We could assume that there is a kind of strange attractor, a quasi - natural ejector, in island's substratum, which works on the principle of water jet pump and that there, is probably operated by infiltration of water. This good hypothesis is nevertheless not very probable and very efficient from a hydrodynamic point of view. In addition, it is possible to report that physical conditions of flow through siphons, venturi tubes, and tubular openings in the carbonate rocks could explain the phenomenon. However, judging from the negative head in sinkholes the velocity of fresh water appears to be insufficient to operate a natural jet pump or suggested venturi tubes.

However, the true cause of the phenomenon has not been elucidated so far. It seems that this throughout Cephalonia current will continue to challenge and to puzzle us continuously. Probably such strange phenomena affected the ancient Greeks in their ideas about common water origin and the holistic movements of all surface and ground waters. The principle of equilibrium due to the difference in density between fresh water and sea water in coastal areas could play an important role in lateral encroachment of sea water in carbonate rocks and also in the vertical movement of salt water through solution openings at the island. It is well known that a fresh-water head, of about $1 \mathrm{~m}$ above sea level, would be sufficient to balance a $40 \mathrm{~m}$ column of salt water.

We could assume that there is a kind of strange attractor. This attractor is a quasi - natural ejector, in island's substratum, which works on the principle of water jet pump. This is probably operated by infiltration of water $[6,7,8]$. This good hypothesis is nevertheless not very probable and very efficient from a hydrodynamic point of view. The strange canal conducting seawater inland at Cephalonia has been a real puzzling problem for centuries. According to local tradition this strange flow fooled ancient inhabitants of the island to believe that local hydrological cycle worked opposite to what we now know and that seawater flowed upwards, losing its "earthy" component along the way and becoming increasingly fresh and "light", to the point of becoming gaseous in high mountains". Observing seawater flowing through the entry canal near Argostoli and disappearing in a system of katavothres, they erroneously concluded that it must flow through the interior of the island, where it looses its "earthy" component, thus becoming the pure water that could be observed at the springs in the foothills. As seen in Fig. 5 the clouds often observed at the relatively high mountainous volume of Ainos further supported this idea. They took this as a clear indication that this water was in fact transformed into clouds when reaching mountaintops, thus closing the hydrological cycle. In the same figure shown is another explanation of the coastal cross-flow current by analogy to a jet pump. According to this analogy high velocity fresh water sucks seawater creates a strong Venturi effect able to power the whole mechanism. 

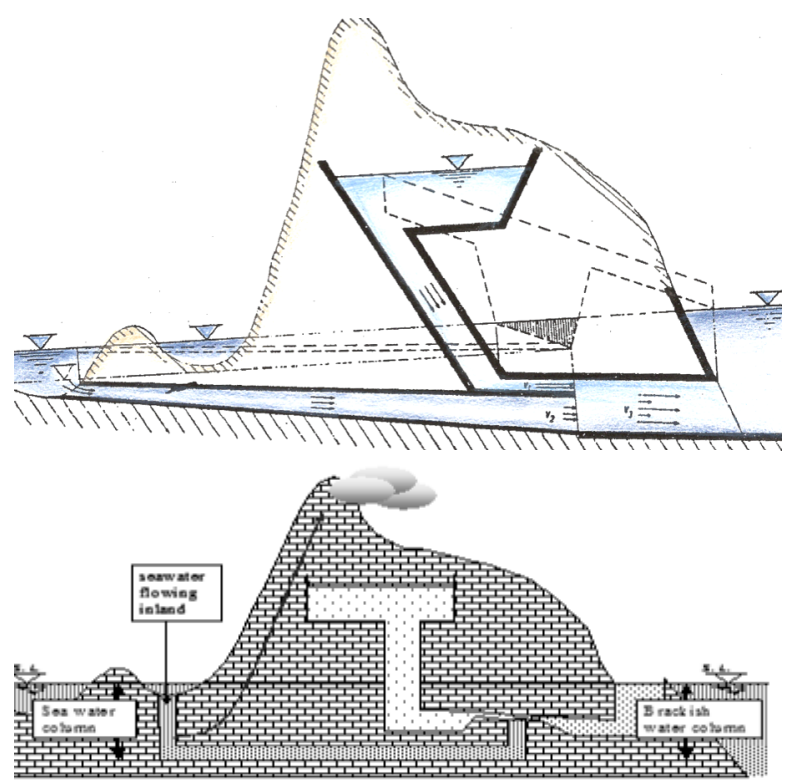

Fig. 5. Representations of hydraulic hypothesis for the local explanation the Cephalonia coastal paradox.

\section{The Tidal Problem of Euripus Strait}

Gravitational forces between moon, sun and earth, cause the rhythmic rising and lowering of ocean waters around the world and the creation of tide waves. The moon exerts more than twice great force on tides as the sun due to its much closer position to earth. As a result, the tide closely follows the moon during its rotation around the earth, creating diurnal tide and ebb cycles at any particular ocean surface. The amplitude or height of tide wave is very small in the open ocean where it measures several centimetres in wave's centre distributed over hundreds of kilometres. However, tide can increase dramatically when it reaches continental shelves, bringing huge masses of water into narrow bays and river estuaries along a coastline. The highest tides, called spring tides, occur when the moon, earth and sun are positioned close to a straight line (moon syzygy). The lowest tides, called neap tides, occur when the earth, moon and sun are at right angles to each other (moon quadrature).

The development of tidal science began in Antiquity, with Aristotle's cosmology, who observed that 'ebbings and risings of the sea always come around with Moon and upon certain fixed times'. Aristotle used his books "On the Heavens and Physics" to put forward his notion of an ordered universe divided into two distinct parts, the earthly region and heavens $[2,3,7]$. The earthly region was made up of the four elements, earth, water, air, and fire. Earth was the heaviest, and its natural place was the centre of cosmos, and for that reason, Aristotle maintained, the Earth was situated at the centre of cosmos. The heavens, on the other hand, were made up of an entirely different substance, called the ether, and the heavenly bodies were part of spherical shells of ether from Moon out to Mercury, Venus, the Sun, Mars, Jupiter, Saturn, and the fixed stars. Aristotle argued that the orbits of the heavenly bodies were circular and that they travelled at a constant speed. Ingenious as this cosmology was, it turned out to be wholly unsatisfactory for astronomy. Heavenly bodies did not move with perfect circular motions: they accelerated, decelerated, and in the cases of the planets even stopped and reversed their motions. Although Aristotle and his contemporaries tried to account for these variations by splitting individual planetary spheres into components, these constructions were very complex and, ultimately, doomed to failure. Furthermore, no matter how complex a system of spheres for an individual planet became, these spheres were still centred on the Earth. The distance of a planet from the Earth could therefore not be varied in this system, but planets varied in brightness. Since variations in intrinsic brightness were ruled out, and since spheres did not allow for a variation in planetary distances from the Earth, variations in brightness could not be accounted for in this system.

Other developments in tidal science at this time included those by Pytheas, who travelled through the Strait of Gibraltar to the British Isles and reported the half-monthly variations in the range of the Atlantic Ocean tides, and that the greatest ranges occurred near the new and the full Moons. Many other aspects of the relationship between tides and the Moon are noted in Pliny the Elder's "Natural History" [2, 3]. Pliny described how the maximum tidal ranges occur a few days after the new or full Moon, and how the tides at the equinoxes in March and September have a larger range than those at the summer solstice in June and winter solstice in December.

Tidal flows are very weak in Eastern Mediterranean, and Euripus strait is a remarkable exception. Tidal flow peaks at about $12 \mathrm{Km} / \mathrm{h}$, either northwards or southwards, and lesser vessels are often incapable of sailing against it. When nearing flow reversal, sailing is even more precarious because of vortex formation. The whole problem has not yet been given a general and complete solution. Some of the questions associated with this subject have been correctly explained, but not always with completeness and the required scientific proofs, others were given a bad solution or misunderstood, while others have been quite ignored, owing to the lack of the necessary tidal data and some had not been studied at all. The Swiss scholar F.A. Forel helped to solve the Euripus tidal enigma owing to his study of the seiche phenomenon.

However, the complete solving of the problem is due to D. Eginitis, who published his conclusions in 1929, in a paper published in the Memoirs of the Academy of Athens[7, 9]. It seems that Eginitis gives the general solution of this famous Euripus tidal problem, with all the proofs provided by the theory and the observations, based on laws of Hydrodynamics and Celestial Mechanics and the respective rules of Hydraulics, taking into consideration the tide observations made by the Hydrographical Service of Ministry of Marine. According to Eginitis, the problem of the tide of Euripus is associated with several questions, the principal of which are:

1. the origin of the tide,

2. the cause of the regular current which near the syzygies of the Moon during 23-24 days of the lunar month is streaming in the channel of Euripus regularly, during about $6 \mathrm{~h}$ towards $\mathrm{N}$ from about the middle of the flood to about the middle of the ebb and during about $6 \mathrm{~h}$ towards $\mathrm{S}$ from the middle of ebb to the middle of flood,

3. the cause of the irregular current which during the remaining 5-6 days of the lunar month near the quarters of the Moon is streaming irregularly, changing direction many times in the day without obeying any law or rule whatever.

4. the shortness of the daily period of the tide amounting to $24 \mathrm{~h} 22 \mathrm{~min} 28 \mathrm{sec}$ only near the syzygies of the Moon.

5. the inversion of the times of the tide, the first flood observed immediately after the end of the irregular 
period corresponding to the time of an ebb, as if one ebb had been omitted,

6. the great difference in the times of establishment of the two ports of Chalkis situated on either side of the channel of Euripus at a distance of a few metres only from each other,

7. the place of the mean level of the two ports,

8. the difference of the height of the level at which the $\mathrm{N}$ and $\mathrm{S}$ currents change direction,

9. the difference in the duration of these two currents,

10. the difference in the influence, which the wind has from time to time on the duration, the velocity and the height of the current,

11. the continuously multiple fluctuation of the two ports of Chalkis and especially of the $\mathrm{S}$ one, and

12. the fact that the durations of the flood and ebb are nearly equal with a small excess of the flood, which is contrary to the phenomenon of the very marked excess of the duration of the ebb, as it is generally observed near the coasts.

It seems that the tide observed in Euboea's gulf is nearly exclusively derivative, and it is produced not only by a local tide of the Aegean Sea as up to this time it was erroneously thought to be, but it comes from Eastern basin of the Mediterranean Sea which is simultaneously fluctuating with Western Mediterranean. On this latter there is a slight influence of the tides of the Atlantic Ocean. So Aegean Sea could be considered as a gulf of Eastern Mediterranean, through which its tide is transmitted to the gulf of Euboea entering it through its two ends and so reaching Euripus. Without this tide, coming from the Eastern basin of Mediterranean Sea, the great $1 \mathrm{~h} 25 \mathrm{~min}$ time lag of the currents arriving in the two ports of Chalkis, situated at a distance of few metres, remains in suspense. On the other hand no serious contradictions might not be put forth against this theory nor could it be supported that derivative tides cannot come from neighbouring basins. Moreover, the ratio of the harmonic waves S2: M2 of Aegean Sea exactly is coinciding with that of Eastern Mediterranean as well as with that of the two ports, after a respective increase in the two gulfs ratifies on the contrary the exactness of such an origin of Euripus tide. The identity of this ratio, as it is well known constitutes the most important and indispensable characteristic of the derivative tides. In addition, the time of establishment of Aegean's sea different points and particularly of Skiathos port, according to simultaneous observations made there and at Chalkis pleads very strongly in favour of this theory correctness. If this wave came from Aegean Sea, it would be perpendicular to the $\mathrm{S}$ end of Euboea and Skiathos and consequently the times of establishment of these two points would be equal. The nature and the causes of Euripus regular current have been probably erroneously explained by Forel, who supposed, without giving any proof, that the S current is produced by the flood in Aegean Sea and the $\mathrm{N}$ one by its ebb. This current may be produced owing to uniform fluctuation in the whole gulf of Euboea, in accordance with channel tides theory. This may be produced in consequence of Chalkis two ports differences as was supposed by Eratosthenes and Endros, in ancient times, but also without any proof. Eginitis has theoretically proved that this current is the second result of the above cases, because a uniform fluctuation of Euboea's gulf is impossible owing to friction in general and the Euripus narrowness channel. Consequently, the two ports are fluctuating independently from each other and therefore the difference in their levels is the cause producing the regular current. Up to this time, no proof supported by the observations has ever been given to the above negative conclusion of the uniform fluctuation theory. Similarly, no proof either theoretical or observational has ever been given for positive conclusion that the current is due to the difference in levels. Such safe certification founded on the tidal phenomena observed in Euripus, as much necessary as indispensable for the completion of the first conclusion and the adoption of the second, is deduced from several proofs given by the observations as follows: a) from the great difference of the time of establishment of Chalkis two ports a few metres only apart from each other; this difference would be impossible in the case of uniform fluctuation. b) from the fact that immediately after the $\mathrm{N}$ current stops, two simultaneous currents stream in the $\mathrm{S}$ port in opposite directions. This shows that the regular current is obviously produced only by the difference of the levels of the two ports, c) from the fact that the change of the direction of the current occurs at heights much differing from that of the mean level and at times much diverging from that of the mean tide in contradiction with the facts required by the theory of the channel tides, d) from the fact, shown also by the observations, that the duration of the flood surpasses slightly that of the ebb, instead of having the duration of the ebb exceeding that of the flood, as it is required by the theory of channel tides, and e) from the coincidence of the times of the maximum velocity of the flood and ebb instead of a marked difference between them, owing to friction effect, as required also by the same theory. According to Eginitis, Eratosthenes also considered that the difference of the sea level on either side of the straits is the cause of the tides observed therein. Moreover, Eratosthenes suggested that the currents of the Messina straits are also due to the same cause. There, as well as in Euripus, a great difference of the sea levels is really observed within a small distance. This is in conformity with the theory according to which the two basins of the Mediterranean, separated by the straights of Messina and that between Sicily and Tunis, are fluctuating simultaneously and therefore the difference in the times of establishment on either side of these straits amounts to many hours.

The great difference of the levels of the two Chalcis ports sometimes observed near Moon syzygies is principally and nearly exclusively due to the great difference of water quantities which according to our calculations is running through Aegean Sea and the two mouths of Euboea's gulf in Chalkis two ports during the flood. In fact, if we compute by means of Hydrodynamics respective equations the water quantities, which at that time reach there, we see that the theoretical values so found of the height of the high water in these two ports and in Aedipsos harbour are in fair agreement with those given by observations. Another reason which partially, but in a considerably smaller degree, contributes to this difference and consequently to the production of the regular current is the topographic configuration of the two ports. Except these two systematic causes there are of course many others such as the wind, the barometric pressure difference, and generally the irregular fluctuations or seiches produced by such local or other effects; these however are taking place only in exceptional cases. However, the duration, height and velocity of the regular current are very sensibly influenced by them and particularly by the wind. Although there is an ancient tradition mentioned also by some ancient and modern authors stating that Aristotle committed suicide in Euripus 
because he could not solve its problem, nevertheless as it is shown from his Meteorologicals. He has been the first among the ancients who solved this problem but only with regard to the question to which the whole problem of Euripus tide was limited from the early times up to the middle of the $19^{\text {th }}$ century, viz. its irregular current. As it is clearly understood from a passage of his Meteorologicals, Aristotle explained the irregular currents not only of Euripus, but also generally of all the sea straits, by the seiches. The same correct solution as we have seen above had been given by Eratosthenes, and in a more general manner. Forel has suggested the same solution in the last century, although he started from erroneous observations and computations and inexactly supposed the $\mathrm{N}$ instead of the $\mathrm{S}$ port as the source of these currents. As it is evident from other ancient passages, Aristotle knew also some of the most important causes of the seiches, such as the wind and the earthquakes. But Forel also, as we have shown, did not find all their causes, neither distinguished that except the seiches there are more other causes, systematic or accidental, giving birth to the irregular current. In the passage quoted above Aristotle in order to explain the great width of the tide in the straits, formulated quite correctly the hydraulic law of the increase of the height of the current in the gulfs, by the entrance of the waters in a narrower and shallower space, viz. exactly as this law is given nowadays. According to the theory of the tide in the channels, the velocity of the current in the channel is a function of the height of the tide, and the different phases of the tide are transmitted with the velocity of the current.

Therefore, the flood duration and ebb depends upon tide's height. However, in Euripus current velocity as well as the flood duration and ebb is a function of the difference between two ports height. For this reason, they do not present the difference usually observed at the coasts, as they are not controlled by the law of tide's height change. As a general conclusion, it follows that, the problem of Euripus tide is associated with several questions and with the continuous presence of Aristotle and Archimedes (see Fig. 6). Some of these questions are peculiar and others, in the majority common to all tidal problems, but none of them is surpassing the power tides theory.

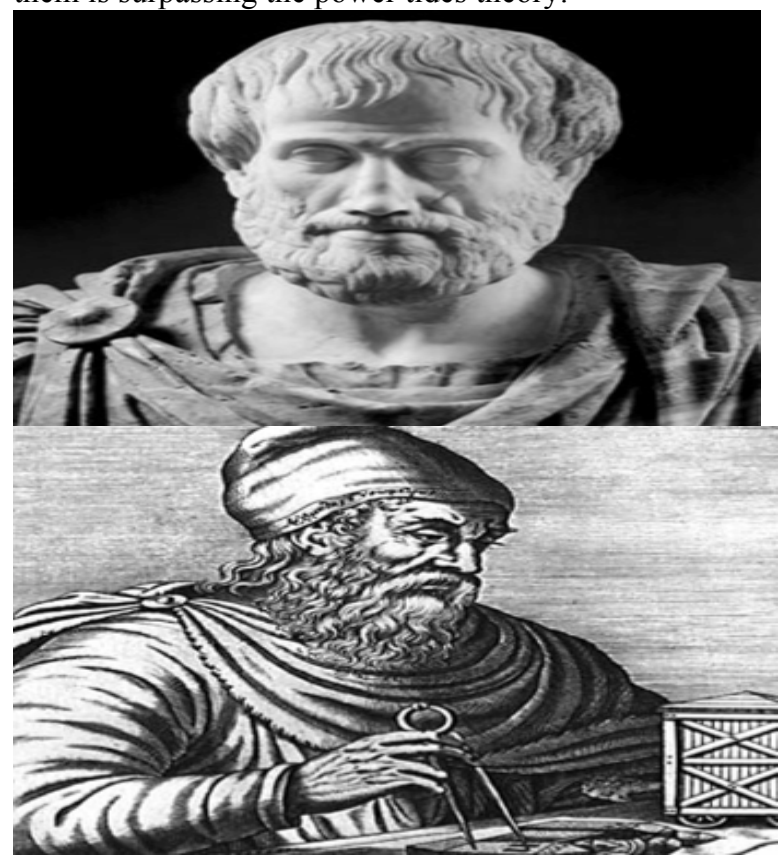

Fig. 6. Aristotle and Archimedes in the Euripus Strait.

\section{Towards Horizontal Archimedean Floating Wheels}

In order to be able to utilize the low and very low water head differences and to recover valuable energy, including seawater and tidal potential, different types of water wheels were developed and perfected in the past. Fig. 7 gives two different horizontal floating water wheels in Euripus Strait.
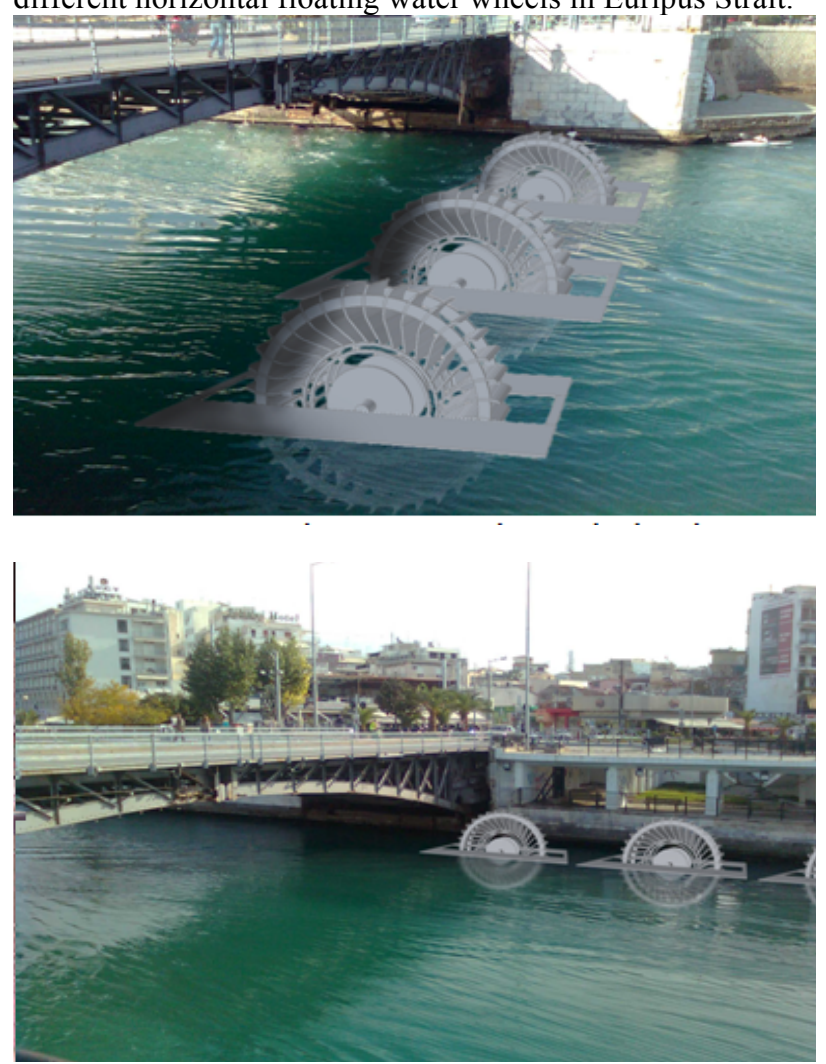

Fig. 7. Horizontal Floating Water Wheels in the Strait of Euripus.

During the last years, an important research effort was made from NTUA and ASPETE towards the rediscovering of the always-modern Archimedean ideas under Archimedean's spiral rotors form and new Archimedean small hydropower plants [9]. Hydraulic Department of ASPETE had made experimental and theoretical research towards the inversion of the energy flow in Archimedean screw operation, and transforming the old Archimedean's screw pump into a new Archimedean screw turbine, a powerful generator for the extraction of tidal and sea current hydraulic energy. This recent work proves that it is technically possible to obtain the optimal exploitation of coastal and continental hydropower potential by considering, that Archimedean screw turbines could be efficient for zero head maritime applications and for various low head sites for different flow rates scales. This effort proves that it is technically possible to obtain the optimal exploitation of small hydro-potential by considering, that Archimedean screw turbines could be efficient for various water heads and for a large scale of flow rates. Some innovative small-scale models of new Archimedean turbines were designed, by following the similarity methodology of the Buckingham's $\pi$-theorem. These models shown in Fig. 8 are tested in an Armfield open channel. An artistic view of an Archimedean cochlear rotor in the open channel of Aspete's Hydraulic Department is given in the same figure. 


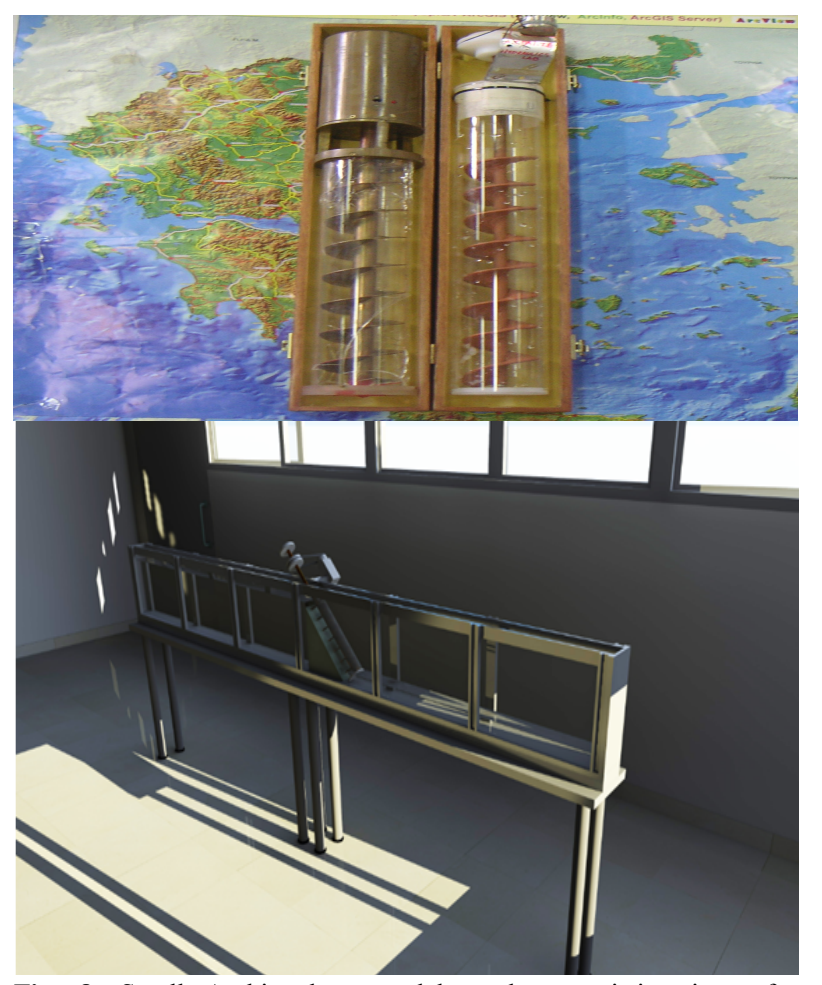

Fig. 8. Small Archimedean models and an artistic view of an Archimedean cochlear rotor in a hydraulic channel.

Such floating Archimedean systems, utilizing the sea and tidal kinetic energy available may operate in unidirectional and/or bi-directional tidal flowing waters and they do not require waves for operation.

A series of such floating Archimedean energy screws could be installed for recovering the hydraulic kinetic energy.

A photorealistic view of such a floating Archimedean spiral hydro-generator, given in Fig.9, represents and simulates the very promising current potential of irrigation channels and marine current flows. The same type of horizontal floating Archimedean spiral rotor without civil word should be tested in the entrance and exit of the natural canal of Cephalonia's mysterious sea river current as well in tidal Euripus conditions. Photorealistic views of floating Archimedean energy screws in Euripus Strait and in the entrance of Cephalonian paradox are represented in Fig.10.

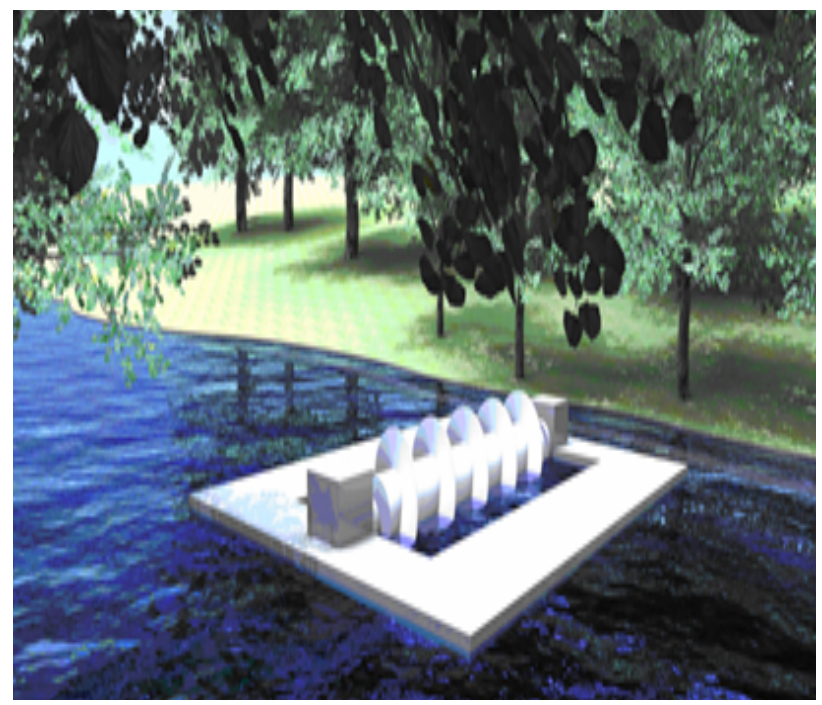

Fig. 9. Photorealistic view of a floating horizontal-axis Archimedean hydro plant.

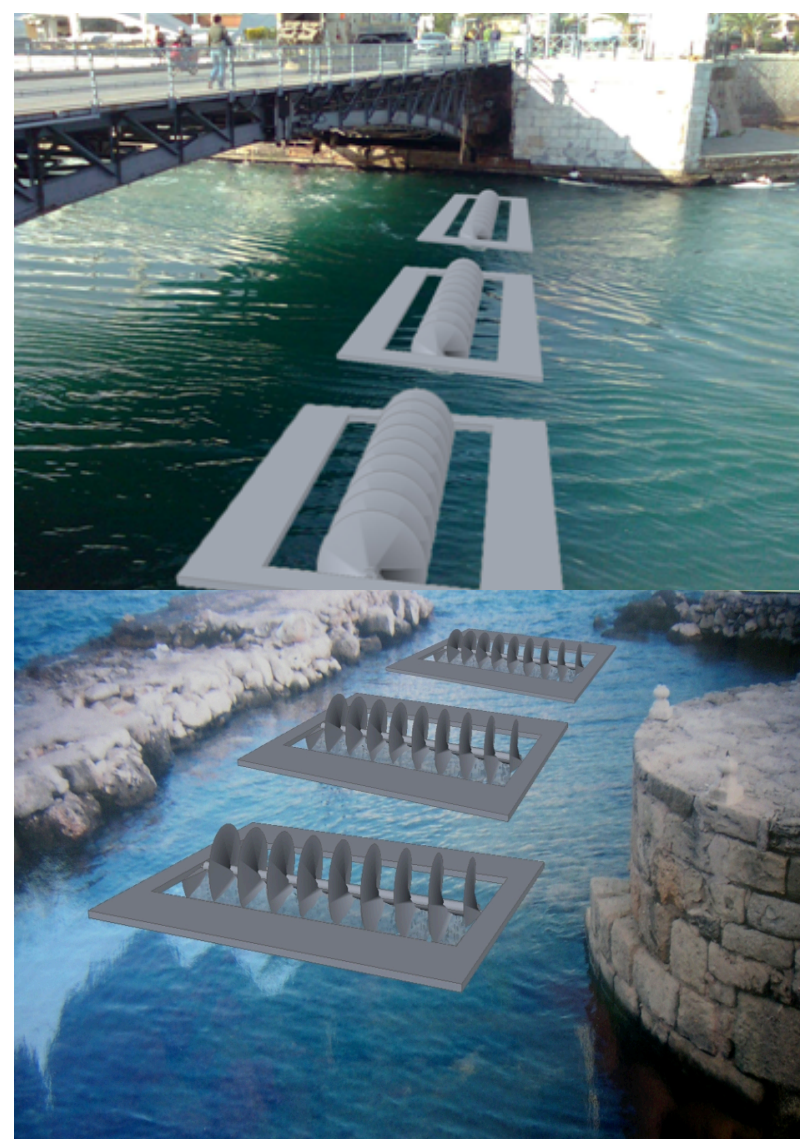

Fig. 10. Artistic views of floating Archimedean energy screws in Euripus strait and Cephalonia.

\section{Preliminary Conclusions from the Archimedes Presence in Cephalonia and Euripus}

There is a growing interest and market for "green" energy derived from renewable energy resources throughout Aegean and Ionian Seas including sea waves, tidal and marine currents, with many countries offering important incentives and targets. With the technical virtual presence of Archimedes, in Cephalonia and Euripus, for recovering the sustainable power of these exceptional local sea river and tidal current singularities, we have been concentrated on the search of the true causes of the coastal Cephalonia's flow paradox and of Euripus tidal phenomenon. The final task is the optimal "Archimedean" exploitation of the important unexploited local tidal potential. The present common N.T.U.A.-ASPETE Archimedean research proves that the massive flow of the Cephalonia paradox and Euripus tidal phenomenon are sufficiently powerful to drive a series of horizontal floating Archimedean spiral water wheels. This research proposes a series of innovative horizontal floating Archimedean water current turbines. A series of floating Archimedean energy screws, under the form of real Archimedean small hydropower farms, without civil works, could be installed for recovering Cephalonia and Euripus hydraulic kinetic energy producing valuable marine renewable electricity. Some first models of floating Archimedean hydro-generators had been "virtually" tested in open channels having a good hydrodynamic behavior giving some very promising preliminary results [10]. It is seems that, in the shadow of the Archimedes presence in Cephalonia and Euripus, the Ionian flow paradox and Aegean tidal flow will continue to keep well the local Gaia Aegean and Ionian water memory secrets. 


\section{Acknowledgements}

This research, as part of the project "Rebirth of Archimedes: Contribution to the study of hydraulic mechanics and hydrodynamic behaviour of Archimedean cochlear waterwheels, for recovering the hydraulic potential of natural and technical watercourses, of maritime and tidal currents", has been co-financed by the European Union (European Social Fund - ESF) and Greek national funds through the Operational Program "Education and Lifelong Learning" of the National Strategic Reference Framework (NSRF) - Research Funding Program ARCHIMEDES III (Investing in knowledge society through the European Social Fund)

\section{References}

1. KE. Moglo, A. Shirazi-Adl, Knee, 10, 265 (2003)

2. T. Zantop, W. Petersen, F.H. Fu, Operative techniques in orthopaedics, 15, 20 (2005)

3. JH. Lo, O. Muller, M. Wunschel, S. Bauer, N. Wulker, J. Biomech. 41, 1855 (2008)

4. R.S. Jones, N.S. Nawana Pearcy, D.J.A. Learmonth, D.R. Bickerstaff, J.J. Costi, R.S. Paterson, Clin. Biomech, 10, 339 (1995)

5. S.L.Y. Woo, R.J. Fox, M. Sakane, G.A. Livesay, T.W. Rudy, F.H. $\mathrm{Fu}$, Knee, 5, 267 (1998)

6. M. Viceconti, S. Olsen, K. Burton, Clin. Biomech. 20, 451 (2005)

7. A. Huson, C.W. Spoor, A.J. Verbout, Acta Morphol. Neerl. - Scand. 24, 45 (1989)

8. M.Z. Bendjaballah, A. Shirazi-AdI, D.J. Zukor, Knee, 2, 69 (1995)

9. F. Bonnel, J-P. Micaleff, Surg. Radiol. Anat. 10, 221 (1988)

10. R.R. Bini, F. Diefenthaeler, C.B. Mota, J. Electromyogr. Kinesiol., 20, $102(2010)$

11. A.E. Yousif, S.R.F. Al-Ruznamachi, 25th Southern Biomedical Engineering Conference. IFMBE Proceedings, 24, 227 (2009)

12. Y. Song, R.E. Debski, V. Musahl, M. Thomas, SL-Y Woo, J. Biomech., 37, 383 (2004)

13. M. Veselkoa, I. Godler, Comput. Biol. Med., 30, 299 (2000)

14. A.A. Amis, T.D. Zavras, Knee, 2, 5 (1995)

15. F. Giron, P. Cuomo, A. Edwards, A.M.J. Bull, A.A.P. Amis, P. Aglietti, Arthroscopy, 23, 7 (2007)

16. L.S. Beasley, D.E. Weiland, A.F. Vidal, A. Chhabra, A.S. Herzka, M.T. Feng, R.V. West, Oper. Tech. Orthop ,15, 5 (2005)

17. G. Stefanoudakis, Greek Patent GR20060100567 (2008)

18. G. Stefanoudakis G Greek Patent GR20060100566 (2008)

19. M. Petousis, A. Vairis, N. Vidakis, G. Pappas, M. Koudoumas, Procs of the 6th International Conference on New Horizons in Industry, Business and Education, Santorini, Greece (2009)

20. R. Boyer, G. Welsch, and E.W. Collings, Materials Properties Handbook: Titanium Alloys. ASM International, Materials Park(1994)

21. S.C. Cowin Bone mechanics, CRC Press (1989)

22. S.L.-Y. Woo, A.J. Almarza, R. Liang, M.B. Fisher, Functional Tissue Engineering of Ligament and Tendon Injuries. Book Ch. no 9.
Translational Approaches In Tissue Engineering And Regenerative Medicine, Artech House Publisher (2007)

23. N.D. Reeves, C.N. Maganaris, N. Maffulli, J. Rittweger, Journal of Biomechanics 42, 797 (2009)

24. O. Lopez, G. Li, H. Rubash, ASME Journal of Biomechanical Engineering 123, 341 (2001)

25. G.E. Lutz, R.A. Palmitier, K.N. An, E.Y. Chao, J. Bone. Joint. Surg. 75,732 (1993)

26. D.E. Toutoungi, T.W. Lu, A. Leardini, F. Catani, J.J. O'Connor, Clin. Biomech. 15, 176 (2000)

27. W. Mesfar, A. Shirazi-Adl, Knee 12, 424 (2005)

28. V. Mosnegutu, Rev. Roum. Sci. Tech. Ser. Mec. Appl. 53, 227 (2008)

29. D.P. Pioletti, L.R. Rakotomanana, P-F. Leyvraz, Med. Eng. Phys. 21, 95 (1999)

30. D.P. Pioletti, L.R. Rakotomanana, J.F. Benvenuti, P.F. Leyvraz, J. Biomech. 31, 753 (1998)

31. K.F. Bowman, J.K Sekiya, Oper. Tech. Sports. Med., 17, 126 (2009)

32. A. Vairis, M. Petousis, N. Vidakis, G. Stefanoudakis, B. Kandyla, ProcS. IEEE 9th International Symposium on Distributed Computing and Applications To Business, Engineering \& Science (DCABES 2010), Hong Kong (2010)

33. T. Fukubayashmi, P. Torzilli, M. Sherman and R. Warren J. Bone Joint Surg, 64, 258 (1982)

34. A. Kanamori, SL-Y. Woo, B. Ma, J. Zeminski, T.W. Rudy, G. Li and G.A.Livesay The Journal of Arthroscopic and Related Surgery 16,633 (2000)

35. T.J. Withrow, L.J. Huston, E.M. Wojtys, and J.A. Ashton-Miller, The American Journal of Sports Medicine 34, 269 (2006)

36. E. Pena, B,Calvo, M.A. Martınez, M. Doblare Journal of Biomechanics 39, 1686 (2006)

37. J. Suggs, C. Wang, G. Li, Clinical Biomechanics 18, 35 (2003)

38. A. Tsarouhas, M. Iosifidis, D. Kotzamitelos, G. Spyropoulos, T. Tsatalas, and G. Giakas, The Journal of Arthroscopic and Related Surgery 26, 885 (2010) 